\title{
Thermo-Mechanical Treatment on Microstructure and Mechanical Properties of Mg-5.0Sn-1.0Mn-0.4Zr Alloy
}

\author{
Xiaoping Luo ${ }^{1,2}$, Daqing Fang ${ }^{3}$, Baosheng Liu ${ }^{1,2}$ \\ ${ }^{1}$ College of Materials Science and Engineering, Taiyuan University of Science and Technology, Taiyuan, China \\ ${ }^{2}$ Engineering Research Center for Magnesium Alloys of Shanxi Province, Taiyuan University of Science and Technology, \\ Taiyuan, China \\ ${ }^{3}$ College of Materials Science and Engineering, Xi'an Jiaotong University, Xi'an, China \\ Email:lxpsyx@126.com
}

How to cite this paper: Luo, X.P., Fang, D.Q. and Liu, B.S. (2018) Thermo-Mechanical Treatment on Microstructure and Mechanical Properties of Mg-5.0Sn-1.0Mn-0.4Zr Alloy. Advances in Materials Physics and Chemistry, 8, 44-50.

https://doi.org/10.4236/ampc.2018.81004

Received: November 29, 2017

Accepted: January 21, 2018

Published: January 24, 2018

Copyright $\odot 2018$ by authors and Scientific Research Publishing Inc. This work is licensed under the Creative Commons Attribution International License (CC BY 4.0).

http://creativecommons.org/licenses/by/4.0/

\begin{abstract}
The mechanical properties and microstructure of an as-cast $\mathrm{Mg}-5.0 \mathrm{Sn}-1.0 \mathrm{Mn}-0.4 \mathrm{Zr}$ alloy were investigated during thermo mechanical treatments consisting of hot extrusion, rolling, and ageing at $200^{\circ} \mathrm{C}$. The results indicate that only $\mathrm{Mg}_{2} \mathrm{Sn}$ phases formed in the $\mathrm{Mg}$ matrix, $\mathrm{Mn}$ and $\mathrm{Zr}$ do not cause the formation of any new phases. The average grain size, tensile strength and elongation were $22 \mu \mathrm{m}, 285 \mathrm{MPa}$, and $14.5 \%$, respectively, after extrusion + rolling + ageing treatment (ERA). The mechanical properties of ERA alloys with a peak hardness of $81 \mathrm{HV}$ and $6.7 \%$ are improved compared with those of EA (extrusion + ageing treatment) samples; these changes are attributed to grain refinement and solid solution strengthening, age hardening, and precipitation strengthening.
\end{abstract}

\section{Keywords}

Mg-Sn-Mn-Zr Alloy, Thermomechanical Treatment, Microstructure, Mechanical Properties

\section{Introduction}

Increasing demands to reduce the weight of automobiles and efforts to reduce the emission of greenhouse gases have accelerated the development of lightweight metallic materials. Many scientists have long believed in the promise of Mg alloys in automotive applications for weight reduction while maintaining their mechanical properties. However, the limited mechanical properties and unsatisfactory corrosion-resistance of most of the commonly used $\mathrm{Mg}$ alloys cannot match 
the requirements of many applications [1] [2] [3].

The typical $\mathrm{Mg}$-Al based and $\mathrm{Mg}$ - Zn based alloys are unsuitable for use at temperatures above $150^{\circ} \mathrm{C}$, due to their greatly decreased strength at elevated temperatures, and poor creep resistance [4]. Therefore, enhancing high temperature stability is a key issue for possible high temperature applications. Many approaches have been adopted to address these problems [5] [6] [7]. The most common method for improving high temperature performance is via alloying elements and forming thermally stable precipitates along the grain boundaries to restrict grain boundary sliding during deformation. Some Mg-Sn based alloys have great potential, among heat resistant $\mathrm{Mg}$-alloys for applications using hot components. It has been reported that the Sn element could significantly improve the elevated temperature properties of $\mathrm{Mg}$ alloys via solid solution strengthening and age strengthening [8] [9]. Because of the low cost of the Sn element with a high solid solubility $(14.48 \%)$ at $561^{\circ} \mathrm{C}$, there is the possibility of precipitating a cubic $\mathrm{Mg}_{2} \mathrm{Sn}$ phase in the Mg-rich matrix with decreasing temperature, whose formation during ageing is accompanied by strengthening [10]. Secondly, the $\mathrm{Mg}_{2} \mathrm{Sn}$ phase with a high melting point of $770^{\circ} \mathrm{C}$ plays an important role in thermal-resistant properties, which is higher than that of other strengthening particles, such as $\mathrm{Mg}_{17} \mathrm{Al}_{12}$ phases. In addition, $\mathrm{Mn}$ is the only metallic element which not only generates a compound with $\mathrm{Sn}$, but also precipitates in the magnesium matrix in its elemental substance form. And Mn could be significantly reinforced by the corrosion resistance of $\mathrm{Mg}$ alloys, which are attributed to the formation of $\mathrm{Fe}-\mathrm{Mn}$ compounds to eliminate deleterious $\mathrm{Fe}$ during the melting alloy process. Also, the precipitation of a-Mn within a $\mathrm{Mg}$ matrix also can form Mn-containing inter-metallic compounds to improve creep-resistance [11].

As we all know, a thermo mechanical grain-refinement technique could increase the available amount of a strengthening precipitate, and improve its properties simultaneously. In the present work, we prepared as-cast Mg-5.0Sn-1.0Mn-0.4Zr alloys to perform comparative investigations among different thermo mechanical treatments, which could provide some valuable clues towards improving the mechanical properties of the alloy in the future.

\section{Experimental}

A Mg-5.0Sn-1.0Mn-0.4Zr alloy was prepared using a magnesium-30 zirconium master alloy, pure $\mathrm{Mg}$ (99.95\%) and $\mathrm{Sn}$ (99.9\%) metals, and $\mathrm{MnCl}_{2}$ melted at $750^{\circ} \mathrm{C}$ under protected gas including $\mathrm{CO}_{2}$ and $\mathrm{SF}_{6}$, and poured into a permanent mold with $\Phi 125 \mathrm{~mm} \times 280 \mathrm{~mm}$ dimensions. The thermo mechanical treatment is schematically illustrated in Figure 1. The as-cast $\mathrm{Mg}-5.0 \mathrm{Sn}-1.0 \mathrm{Mn}-0.4 \mathrm{Zr}$ alloys with $90 \mathrm{~mm}$ in diameter were heat-treated (homogenized) at $480^{\circ} \mathrm{C}$ for $10 \mathrm{~h}$, and then extruded at $320^{\circ} \mathrm{C}$, with an extrusion ram speed of $0.1 \mathrm{~mm} / \mathrm{s}$ and an extrusion ratio of 21:1, using graphite spray to reduce friction during extrusion. The extruded samples were age treated at $200^{\circ} \mathrm{C}$ for $100 \mathrm{~h}$ (extrusion + ageing treatment: EA), respectively. As a comparison, before the ageing treatment extruded $8 \mathrm{~mm}$-thick samples were hot-rolled at $320^{\circ} \mathrm{C}$ along the extrusion 


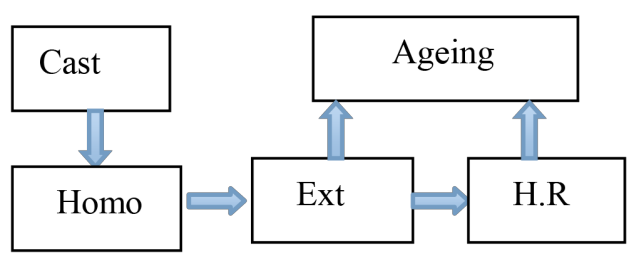

Figure 1. Thermomechanical processing route. Homo = homogenisation; Ext $=$ extrusion; H.R. = hot rolling.

direction with a final thickness of $2.4 \mathrm{~mm}$. The thickness reduction in the hot rolling was $20 \%$ per pass, and rolling speed was $0.5 \mathrm{~m} / \mathrm{s}$. After rolling pass, the sample was treated at $200^{\circ} \mathrm{C}$ for $100 \mathrm{~h}$ (extruded + rolled + ageing treatment: ERA).

The microstructure was examined along the rolled direction (RD) and the extruded direction (ED) using optical microscopy (OM), transmission electron microscopy (TEM), and scanning electron microscopy (SEM, S4800), equipped with energy-dispersive X-ray spectrometry (EDS). The grain sizes were determined using the lineal intercept method; the average of the measured values was used as the grain size of the alloy. All the specimens were polished and etched with a solution of $10 \mathrm{ml}$ of acetic acid, $5 \mathrm{~g}$ picric acid, and $10 \mathrm{ml}$ of water. Thin foils for TEM were prepared after mechanical grinding to $0.1 \mathrm{~mm}$, followed by twin-jet electrical polishing under cooling by liquid nitrogen. Standard tensile tests were performed at a strain rate of $1.0 \times 10^{-3} \mathrm{~s}^{-1}$. The ultimate tensile strength (UTS), yield strength (YS), and elongation to fracture were determined using three samples. The tensile fractured surfaces of the specimens were examined using SEM. The Vickers hardness (HV) was measured using a loading force of $100 \mathrm{~g}$ and a holding time of $20 \mathrm{~s}$.

\section{Results and Discussion}

\subsection{Microstructure Evolutions}

Figure 2 shows the optical micrographs of the experimental as-cast alloys under different conditions. The microstructure of as-cast alloy with an average grain size (AGS) of $204 \mu \mathrm{m}$ is shown in Figure 2(a). In order to eliminate the non-equilibrium phase, a solid solution treatment is employed; the AGS increases slightly to $210 \mu \mathrm{m}$ and most of the secondary phase on the grain boundary is dissolved into the Mg matrix (Figure 2(b)). For the $320^{\circ} \mathrm{C}$ extruded alloy, the AGS is greatly refined to about $120 \mu \mathrm{m}$ during the extrusion process (Figure 2(c)), and the alloy consists of mostly equiaxial grains, which showed remarkable fluctuation. In addition, some fine second-phase particles are distributed in the grains. This result occurred because the forward extrusion temperature mainly affects the nucleation and growth of dynamic recrystallization. In contrast, there is big change in the size and shape of grains in the $320^{\circ} \mathrm{C}$ extruded and $300^{\circ} \mathrm{C}$ rolled alloy (Figure 2(d)). The average grain size is about $60 \mu \mathrm{m}$, the grains remain equiaxed, and their size distribution is similar to those in the as-extruded condition. 



Figure 2. Microstructure of experimental alloy under different conditions. (a) As-cast; (b) Homo; (c) Extruded; (d) Extruded + rolled.

Compared with the above alloys, there are new many deformation twins appearing, acting as primary obstacles against dislocation motion. Because the grain boundary diffusion speed is fast in the hot-rolling process, dynamic recovery does not easily occur.

Figure 3 shows the peak ageing optical microscopy of the alloy at different thermo mechanical treatments. It can be seen that the grain size is more refined in the EA state (Figure 3(a)), and the values of AGS for the alloys are about 50 $\mu \mathrm{m}$ and composed of equiaxial grains. While the value of AGS is about $22 \mu \mathrm{m}$, it is mostly compression twinning and regular polygon grains that are observed in Figure 3(b), owing to the dynamic recrystallization during ERA. The broken secondary phases are mostly distributed along the grain boundaries. However, the grain boundaries are severely deformed along the rolling direction. A number of tangled dislocation accumulations and rod-liked precipitations distributed along the dislocation walls are observed in TEM bright field graphs (Figure 3(c)). Figure 3(d) shows the XRD patterns of different thermo mechanical processing conditions for the alloy, only peaks from $\alpha-\mathrm{Mg}$ and the $\mathrm{Mg}_{2} \mathrm{Sn}$ phase are observed, indicating that only $\mathrm{Mg}_{2} \mathrm{Sn}$ exists other than the $\mathrm{Mg}$ matrix. $\mathrm{Mn}$ and $\mathrm{Zr}$ do not cause the formation of any new phases. The peak intensity and positions of ERA state alloy change toward weak and low angle directions compared with those for EA.

\subsection{Mechanical Properties}

Mechanical tests at room temperature were performed to determine the effect of the extrusion, rolling, and ageing process, and the results are presented in 

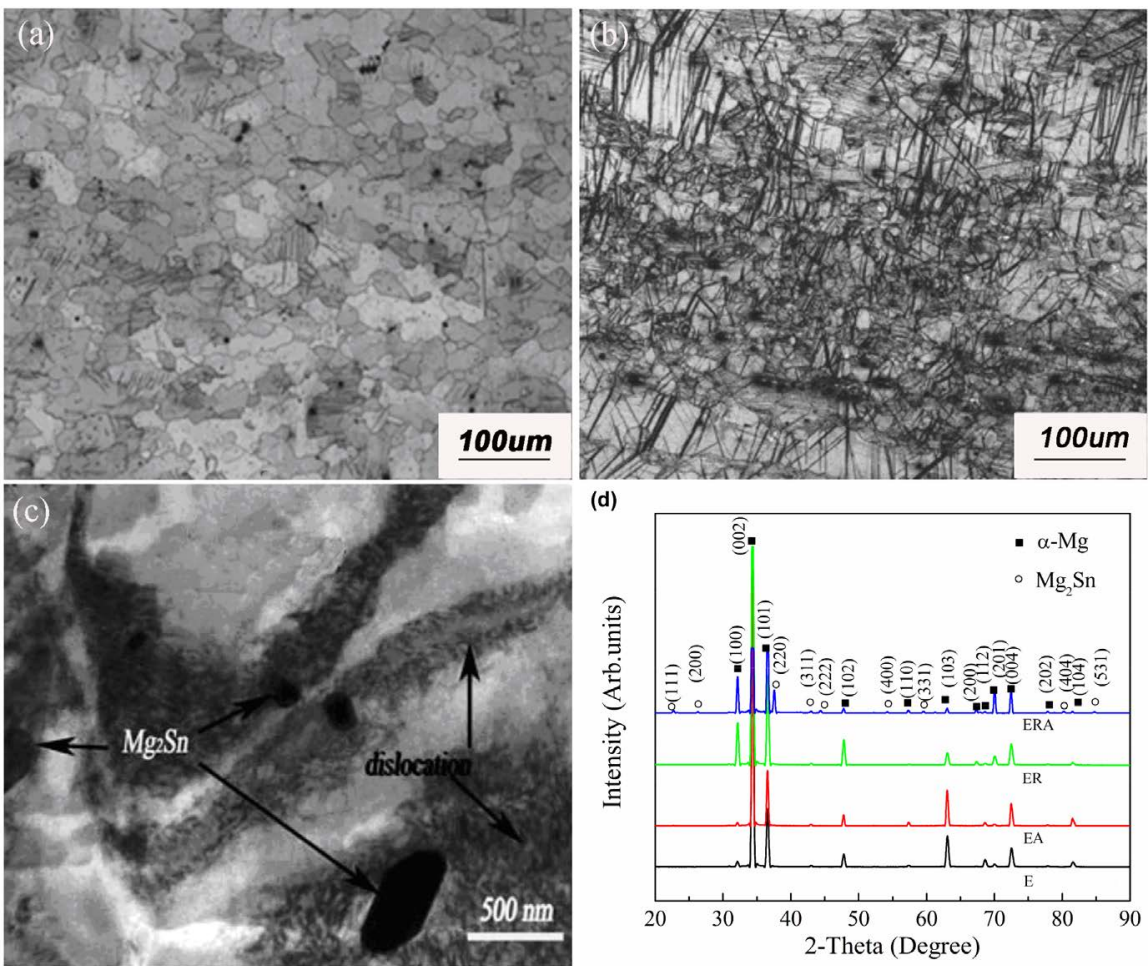

Figure 3. The micrographs and XRD patterns of EA and ERA alloy. (a) Micrograph of EA; (b)Micrograph of ERA; (c) TEM of ERA; (d) XRD patterns of EA and ER.

Figure 4. It can be seen that the additional rolling process can improve the tensile properties. The ERA alloy obtains the highest performance, and its YS, UTS and elongation are $179 \mathrm{MPa}, 285 \mathrm{MPa}$ and $14.5 \%$ respectively, which are mainly related to the grain refinement, twinning and dislocations caused by the plastic deformation containing extrusion and rolling, and the precipitation of fine $\mathrm{Mg}_{2} \mathrm{Sn}$ particles in the ageing treatment. In particular, the dislocations interacting closely with refined $\mathrm{Mg}_{2} \mathrm{Sn}$ precipitates can effectively improve the mechanical properties of the alloy.

Compared with the EA alloy, the hardness of the ERA alloy is $81 \mathrm{HV}$, an improvement of $6.7 \%$, displaying better age-hardening of grain-refinement strengthening. Therefore, it is credible that the tensile properties of the alloy increased sharply because of the accumulated deformation of the ERA treatment in preventing edge cracking of the rolling process.

The tensile fracture surfaces of the peak-aged alloys were analyzed by SEM to infer the microscopic mechanisms controlling the overall fracture response. In Figure 5(a), cleavage steps and a river pattern are observed in the fracture surfaces of the EA sample, indicating the occurrence of the typical cleavage fracture mechanism. Many dimples and tearing ridges are observed on the fracture surface of the ERA alloy (Figure 5(b)). Some second phase particles are observed within these dimples. These deep dimples, which are associated with the drawing of particles, indicate that a certain amount of plastic deformation occurred before rupture. This effect will positively benefit the strengthening behavior 


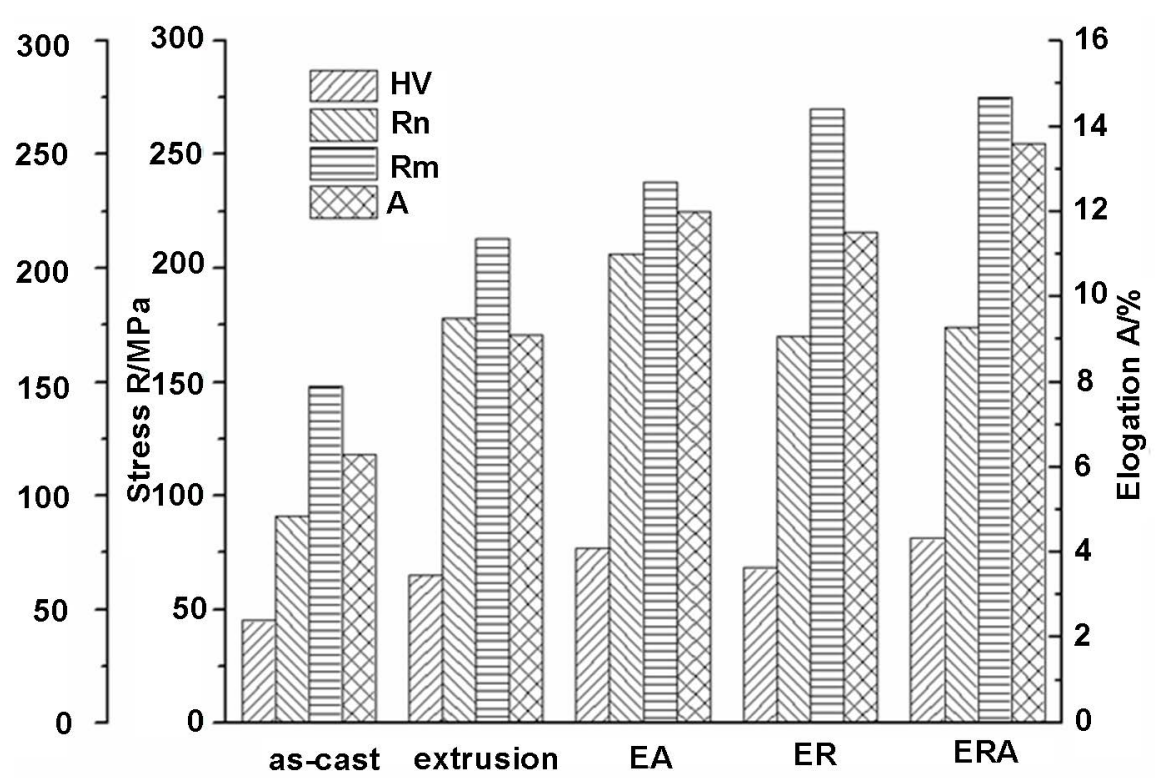

Figure 4. Mechanical properties of experimental alloy in different conditions.
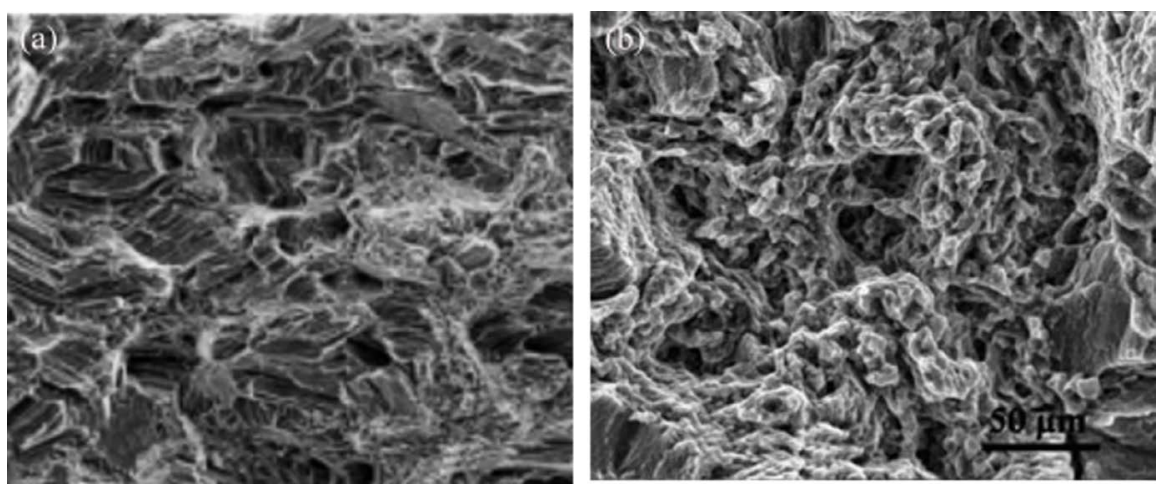

Figure 5. Tensile fracture micrographs of the peak-aged alloys. (a) EA; (b) ERA.

instead of deteriorating the mechanical property because of its more refined microstructure.

\section{Conclusion}

Thermo mechanical treatments were performed on a Mg-5.0Sn-1.0Mn-0.4Zr alloy. After EA of the as-cast alloy, dynamic recrystallization occurred; the tensile strength increased, and the ductility improved. After the ERA process, many twins appeared, dislocations were formed in the interior of the grains, and grain refinement was observed. Also, the hardness reached a maximum value of $81 \mathrm{HV}$, and the tensile elongation increased to $14.5 \%$, which is mainly related to deformation twinning the formation of dislocations during the ER state, and fine $\mathrm{Mg}_{2} \mathrm{Sn}$ precipitates forming in the ageing treatment.

\section{Acknowledgements}

The study was financially supported by both Shanxi Scholarship Council of China 
(No. 2017-082) and the nature science foundation of Shanxi Province, China (No. 201701D121041), and we have no conflict of interest.

\section{References}

[1] Czerwinski, F., Kasprzak, W., Sediako, D., Emadi, D., Shaha, S.K., Friedman, J. and Chen, D.L. (2016) High-temperature Aluminum Alloys for Automotive Powertrains. Advanced Materials and Processes, 174, 16-20. https://doi.org/10.1002/adem.200500013

[2] Song, G. (2005) Recent Progress in Corrosion and Protection of Magnesium Alloys. Advanced Engineering Materials, 7, 563-586.

[3] Watarai, H. (2006) Trend of Research and Development for Magnesium Alloys. Science \& Technology Trend, 18, 84-97.

[4] Zhang, J.H., Zhang, M.L., Meng, J. Wu, R.Z. and Tang, D.X. (2010) Microstructures and Mechanical Properties of Heat-Resistant High-Pressure Die-Cast Mg-4Al-xLa-0.3Mn $(\mathrm{x}=1,2,4,6)$ Alloys. Materials Science and Engineering A, 527, 2527-2537. https://doi.org/10.1016/j.msea.2009.12.048

[5] Wang, Y., Liao, X. and Zhu, Y. (2009) Grain Refinement and Growth Induced by Severe Plastic Deformation. International Journal of Materials Research, 100, 1632-1637. https://doi.org/10.3139/146.110230

[6] Kondoh, K., et al. (2004) Materials and Processing Designs for Magnesium Alloys—Grain Refining by Repeated Plastic Working and Solid-State Synthesis of $\mathrm{Mg}_{2} \mathrm{Si}$ (Review). Advances in Technology of Materials and Materials Processing, 6, 328-335.

[7] Kang, S.H., Lee, Y.S. and Lee, J.H. (2008) Effect of Grain Refinement of Magnesium Alloy AZ31 by Severe Plastic Deformation on Material Characteristics. Journal of Materials Processing Technology, 201, 436-440. https://doi.org/10.1016/j.jmatprotec.2007.11.305

[8] Sasaki, T., Elsayed, F., Nakata, T., Ohkubo, T., Kamado, S. and Hono, K. (2015) Strong and Ductile Heat-Treatable Mg-Sn-Zn-Al Wrought Alloys. Acta Materialia, 99, 176-186. https://doi.org/10.1016/j.actamat.2015.06.060

[9] Nayyeri, G. and Mahmudi, R. (2010) Effects of Sb Additions on the Microstructure and Impression Creep Behavior of A cast Mg-5Sn Alloy. Materials Science and Engineering: A, 527, 669-678. https://doi.org/10.1016/j.msea.2009.08.056

[10] Clark, J.B., Zabdyr, L. and Moser, Z. (1988) Phase Diagrams of Binary Magnesium Alloys. ASM International, Materials Park, OH, 353-364.

[11] Clark, J.B., Zabdyr, L. and Moser, Z. (2001) Phase Diagrams of Binary Magnesium Alloys. Journal of Materials Processing Technology, 117, 276-281. 